\title{
ADVANCEMENT OF SKIN PASS ROLLING
}

Roman Schneeweis ' Karl Berger ${ }^{2}$

Dietrich Mathweis ${ }^{3}$

\begin{abstract}
With increasing demands from customers to provide flat strip with tighter tolerances on material properties, particularly flatness of e.g. martensitic steel grades, it has become necessary to develop strategies to improve flatness without influencing the tensile properties for such hard steel grades. Usual skin pass mills are not capable to apply sufficient tension and roll force for these kinds of material to improve the flatness. Therefore, alternatives had to be searched for. This paper describes skin pass- / temper - rolling methods from the classical one to new alternatives in order to satisfy the demanding market of higher material properties and idle running mills in rolling plants.
\end{abstract}

Keywords: Skin pass rolling; High strength steel grades; Strip flatness.

\section{INTRODUCTION}

By 2030, electric vehicles will be mainstream, not just within the premium segment, as they are today. Electric vehicles will be popular and available across all vehicle variants. Also, fully autonomous or self-driving vehicles are upcoming on the horizon. Market intelligence shows that due to the high cost to municipalities and regional governments, autonomous-only vehicles will be limited to dedicated areas for a long time to come. Because of this passive safety for occupant and now also for battery protection, occupant freedom and lightweight structural design are the main focus in the next years. Steel is needed to meet these requirements. Therefore, new steel grades are developed to meet the needed strength while keeping the material thin, which leads to mass reduction, lower cost, and reduced life cycle emissions (Figure I).

Also, the demands on flatness and material properties required for a cost efficient automated and advanced manufacturing process, applied not only in the automotive industry, leads to tighter tolerances. The achieved flatness after heat treatment and quenching process has to be improved therefore further. These circumstances are leading to process the high strength steel on skin pass mills.

\section{STANDARD SKIN PASS MILL DESIGN}

The standard skin pass mill layout as shown in Figure 2 consists of:

- Uncoiler;

- Entry/exit bridles;
- Mill Stand;

- Recoiler.

Typical technological operation parameters used are:

- Specific roll forces: $0.5 \mathrm{kN} / \mathrm{mm}$ to $8 \mathrm{kN} / \mathrm{mm}(2.5 \mathrm{kN} / \mathrm{mm}$ average) (per strip width);

- Specific tensions: $10 \%$ to $25 \%$ of $\mathrm{kf}$ (yield stress) $\max .300 \mathrm{~N} / \mathrm{mm}^{2}$.

The maximum utilization of a skin pass mill leads to the situation that nearly the whole product range is running on the mill starting at IF-grades up to AHSS grades. For IF-steel grades low roll forces close to the mill stand friction have to be applied (e.g. $500 \mathrm{kN})$.

Roll forces of high strength steel grades coils are reaching the maximum design force of the roll load cylinders. Due to this fact the controller and presetting of the mill is quite non-linear and has to be considered at the control and process model design.

\section{I Technological Setting}

Most crucial for a cost and production efficient operation of a skin pass mill with tight tolerances are flatness settings and control strategy. Due to the fact, that the load condition is varying from close to the mill stand friction to maximum design force load the correlation between bending and roll force becomes non-linear. Only at higher mill stand loads the bending roll force behavior gets linear (Figure 3).

The theoretical method to model the roll gap profile used is the state of the finite element method (FEM) and finite volume method (FVM). The FEM method is used to

'pa-innovations GmbH, Linz, Austria. E-mail: roman.schneeweis@pa-innovations.com

${ }^{2} K B$.IC Consulting, Linz, Austria.

${ }^{3}$ Mathweis Engineering GmbH, Düsseldorf, Germany.

2176-1523 (C) 2020. Schneeweis et al. Published by ABM. This is an Open Access article distributed under the terms of the Creative Commons Attribution License, which permits unrestricted use, distribution, and reproduction in any medium, provided the original work is properly cited. 


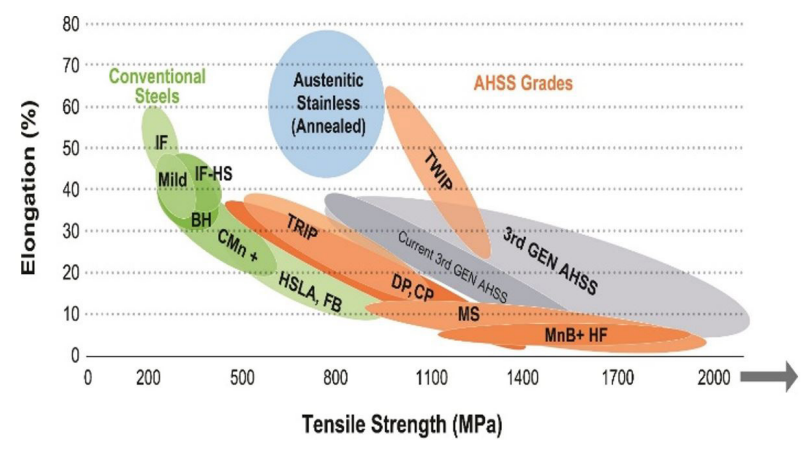

Figure I. Steel Strength Ductility Diagram.

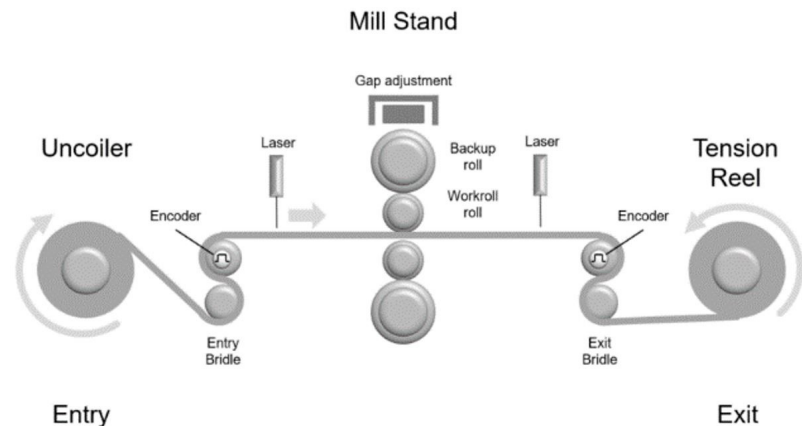

Figure 2. Standard Skin Pass Mill Configuration.

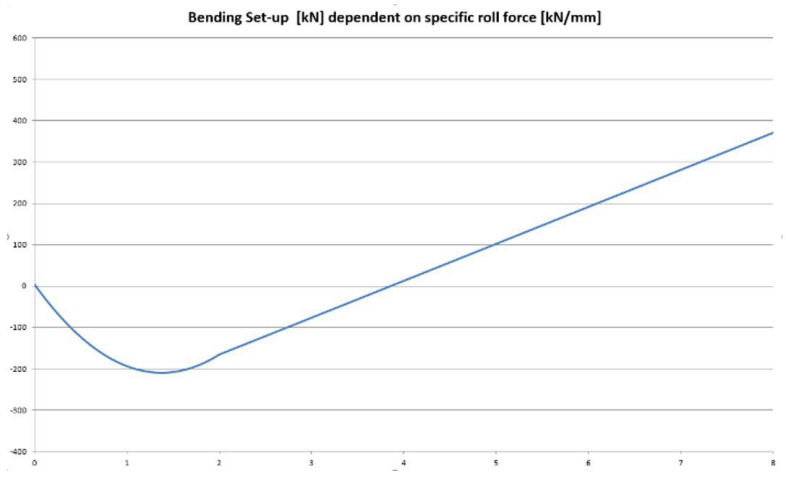

Figure 3. Non-Linear Bending/Roll Force Behavior.

calculate the mechanical deformation of the roll set. The FVM method is used to calculate the thermal distribution in the roll set $[1,2]$.

The individual rolls of the roll set are each modeled as beam elements (Timoshenko beams). Depending on the choice of resolution, a single roll comprises $80-120$ beam elements and as many nodes, where forces or boundary conditions can be applied. When two rolls are in contact with each other (for example, working roll and back-up roll), their respective support points connected to each other in the roll body are represented by elastic pressure bars.

In order to take account of the large cross-sectional areas of the rolls, Timoshenko beam elements were chosen (in contrast to the Bernoulli beam), which take into account not only the axial expansion but also the shear forces between two beam cross sections.
The rod elements used to model a rolling contact are chosen for their rigidity according to the formulas of Hertzian stress [3].

Each element of the thus-modeled mechanical system has an element stiffness matrix. For the overall system, all individual element matrices are in superposition to a total stiffness matrix. With the vector of the pointwise external loads (e.g. roll force) and the vector of the pointwise shift amounts, the linear system of equations is formed. The initially unknown shift amounts are calculated by inverting the stiffness matrix. Nonlinearities and initial strains (e.g. from solving roll contact, roll grinding, thermal expansion) are considered at the elemental level using the Newton-Raphson [I] method. This results in displacement values for each point of the FEM mesh and the expected contour of the roll gap.

For the calculation of the temperature distribution in the roll set a finite volume method (FVM) is used. The temperature distribution in the individual rolls is assumed to be rotationally symmetrical, so that only the respective cross section of the rotating body has to be crosslinked. In this way, the calculation effort of the complete three-dimensional heat conduction problem can be significantly reduced. However, this simplification is permissible due to the permanent roll rotation during operation.

Heating and cooling processes in the roll set are time-dependent and will therefore be calculated parallel to the process (including mill stops). In addition to the location discretization given by the calculation grid (numerical derivation of the local temperature according to the location coordinates), there is also an implicit time discretization. This method is numerically extremely robust and has additional calculation speed advantages, e.g. compared to an explicit finite difference method. Apart from the aforementioned simplification of the rotational symmetry, the heat conduction in the set of rolls can be completely calculated synchronously to the process.

The calculation of the thermal strain at each width support point is done by accumulation of the element-wise thermal expansion over the radius. The shape and the amount of the thermal crowning results automatically from the temperature distribution without explicit form function.

The wear occurring in the course of a roll travel also has a significant influence on the roll gap geometry and must therefore be taken into account to the calculation. Significant factors influencing wear are load and rolled length. This effect is taken in account by the use of roll length/load dependent strip profile change.

Flatness adaption is based on adapting the incoming strip profile. In order to compensate the incoming strip profile change of the incoming strip created in the hot strip mill for the strip head, body and tail a length dependent profile function is used.

The same functions and methods are used to calculate the flatness actuator settings for the tandem mill.

For skin pass rolling on single stand or on tandem mill a compact model using Taylor series equations based 
on the above-mentioned FEM flatness calculations has been developed.

Figure 4 shows the main components to set the skin pass mill, like:

- Yield stress and thickness dependent tension calculation with auto adaptation;

- Yield stress and thickness dependent non-linear line speed dependent roll force calculation with auto adaptation;

- Bending model, considering strip width, actual line-load, roll diameters, roll crown, roll wear and incoming strip profile with auto adaption of strip profile;

- Strip length dependent incoming strip profile for head, body and tail.
The level I controller for the hydraulic gap adjustment is based on a differential geometric in-output linearization in order to keep the control dynamic load and cylinder position independent (e.g. the control behavior of a hydraulic cylinder gets stiffer by collapsing the cylinder).

\subsection{Market and Economic Environment}

As mentioned before the development and need for stronger and thinner steel leads to the situation that currently installed skin pass mills do not have enough roll force and tension available.

One option is to use cluster rolling mills for skin pass operation (using small roll diameters), which are often not available in-house. A second option would be to invest in a major upgrade of the installed skin pass mill or even to install a new skin pass mill with increased roll force and tension

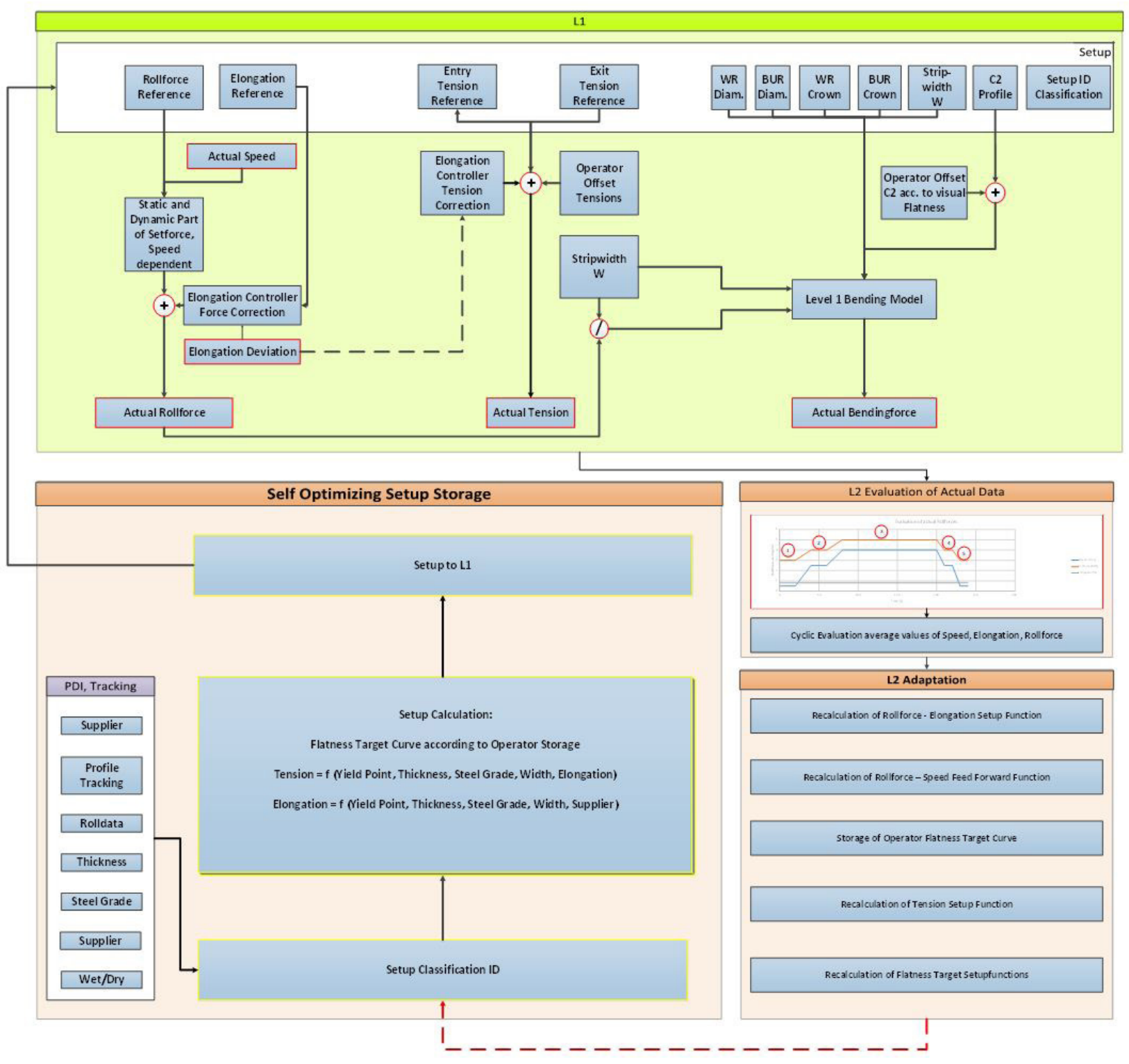

Figure 4. Setting Strategy Skin Pass Mill. 
capabilities (higher investment costs). On the other hand, due to current production overcapacity in-house tandem mills (TCM) are not utilized to their full extent, which leads to additional outage times. Under such circumstances the idea was borne, why not use a tandem mill during its additional outage time for skin pass operation of "high strength" steel grades. Through utilization of the tandem mill enough roll force and tension are available. Instead of applying a total reduction of up to $90 \%$ during normal rolling operation, the mill technological functions have to be modified for skin pass operation, where the total reduction is reduced to $0.3 \%$ to $0.5 \%$.

\section{CONVERSION OF A TANDEM MILL FROM REDUCTION MODE TO SKIN PASS MILL OPERATION}

The operation mode skin pass rolling on the TCM is used to improve the strip flatness of high strength steel with tension strength $>1000 \mathrm{MPa}$ (e.g. martensitic steel grades).

The skin pass rolling is done by the use of either 2 (stand 4 and 5) or 3 mill stands (stand 3, 4 and 5). The number stands used is defined by the L2 strategy table. The mill stands are operated in force control mode. The mill stands not used for skin pass rolling are used as "pinch rolls".

In order to convert a mill stand into a "pinch roll" the following mode and references are used:

- Stand in force control;

- Specific roll force reference value (forces are defined as specific values in the level 2 strategy table);
- Specific inter stand tension approx. $60-100 \mathrm{~N} / \mathrm{mm}^{2}$;

- Inter stand tension control via exit speed.

The tension control for inter stand sections, where mill stands are used for skin pass rolling, is done via the exit speed of the main drive of the tension section. The inter stand tension controller structure has to be changed in such a way that the normal tension controller is used by acting on speed instead of gap. The controller parameters are modified and adjusted for low reduction.

The threading of the mill is done with open mill stands (e.g. $8 \mathrm{~mm}$ gap). They are closed automatically "on the fly" to preset force when the strip head is behind the mill stand. Tailing of mill is done similar to regular operation just the mill stands used for skin pass mill operation are ramped to "pinch roll" reference value during tailing. The trigger point to ramp to the "pinch roll values" is given by the level 2 strategy tables.

The elongation controller is acting on the inter stand tension of the skin pass mill stands to reach the target elongation.

In case of skin pass rolling the flatness control is done by changing the bending and tilting reference values of stand 4 . The segmented roll cooling is not used.

\section{I Inter Stand Tension Control}

The inter-stand tension control of the tandem mill implemented is model based (Figure 5). The dynamic modelling of the inter stand tension used is based on the following principles:

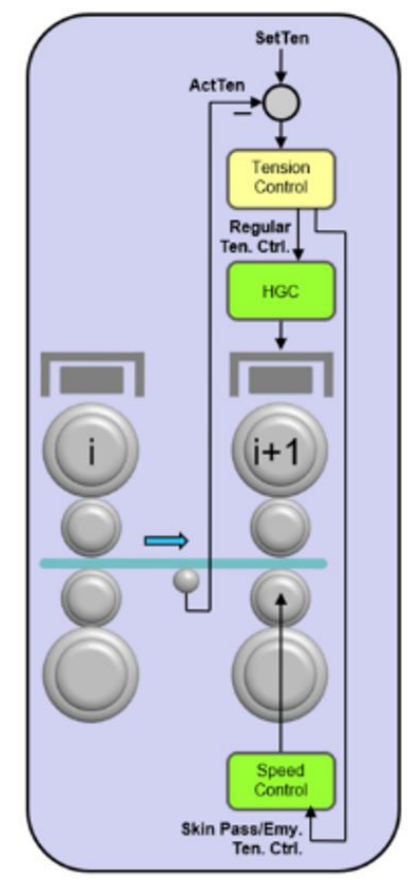

Interstand Tension Control

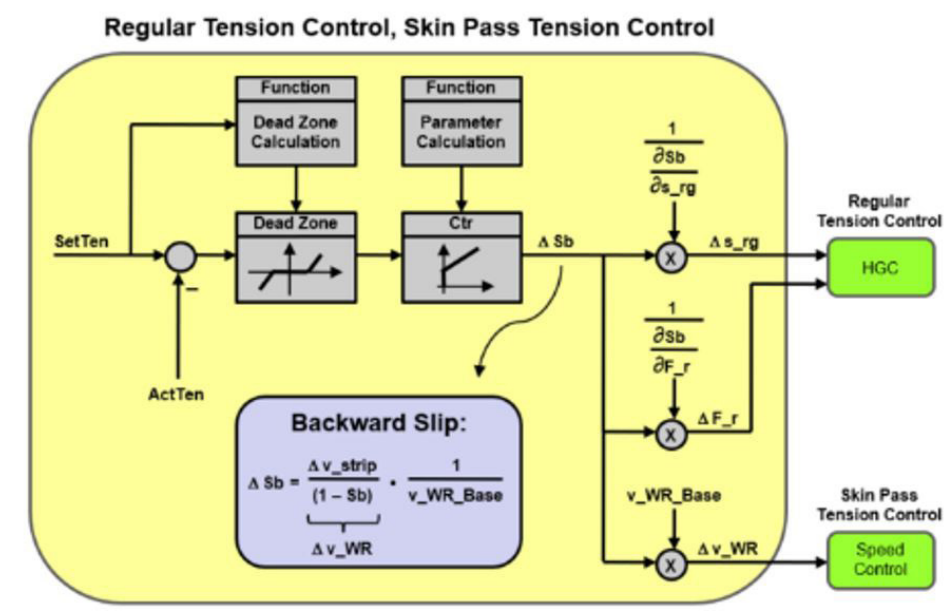

Figure 5. Model Based Inter Stand Tension Control. 
- Hooke's law;

- Forward slip dependency on entry/exit thickness and entry/exit specific tension;

- Mass flow principle.

The target of the controller and decoupling network design is to keep the mass flow through the complete mill constant, even when the roll force is kept constant at the last stand (tandem mill sheet mode). Therefore, the mass flow out of stands $I$ and 5 is compensated by the use of the exit strip speed measurement (laser speed or incremental speed encoder mounted on the tensiometer roll). Furthermore, the forward and the backward tension are controlled simultaneously with stand 4 , thus the total speed correction of the last stand becomes zero.

\subsection{TCM Skin Pass Mill Elongation Control Mode}

The elongation measurement is based on the measurement of the strip length on entry and exit side of the mill by using the existing laser speed measurements. In order to eliminate measurement errors like laser alignment, a zeroing function for the elongation measurement is foreseen. The mill is set for zeroing the elongation like open roll gap at stand 2 to 5 , stand I is closed with "pinch roll force", minimum strip tension at un-coiler and re-coiler and the line is running with thread speed.

The elongation controller (Figure 6) acts on the inter stand tension reference value of the skin pass mill stands. E.g. in case of using the mill stands 3, 4 and 5 the tension reference value for inter stand 34 and 45 is modified to reach the target elongation.

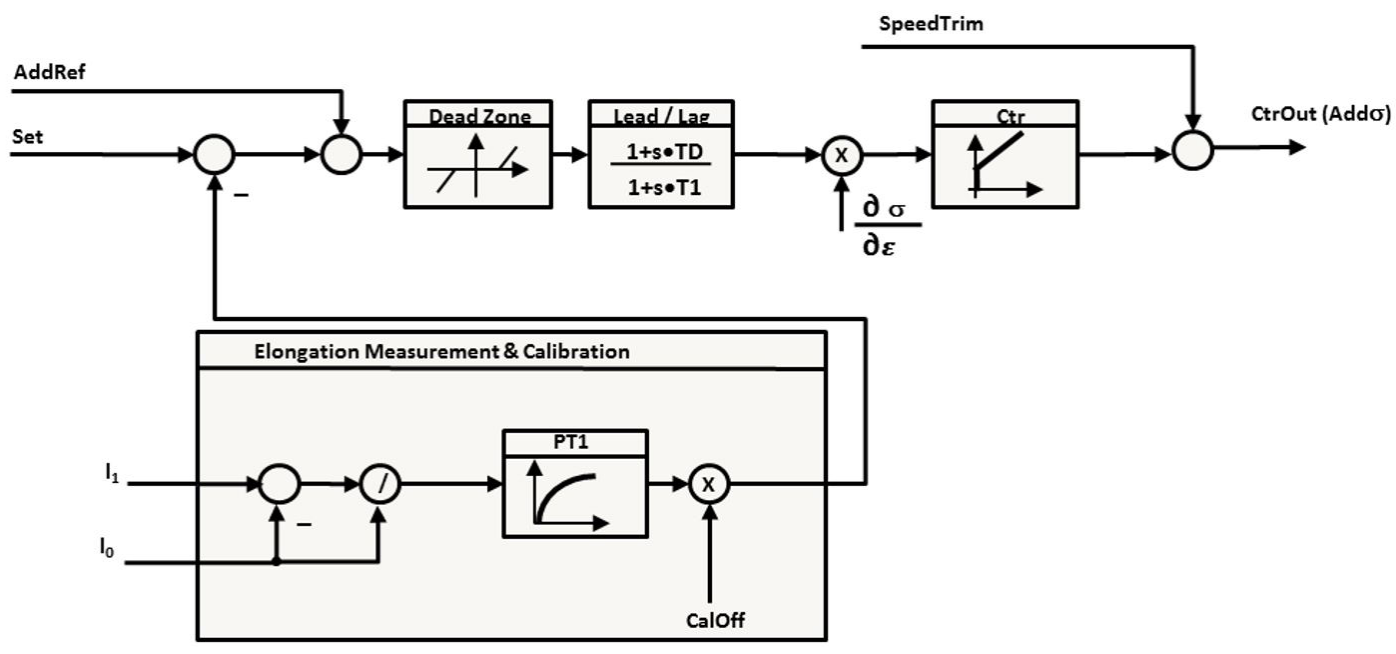

Figure 6. Elongation Controller.

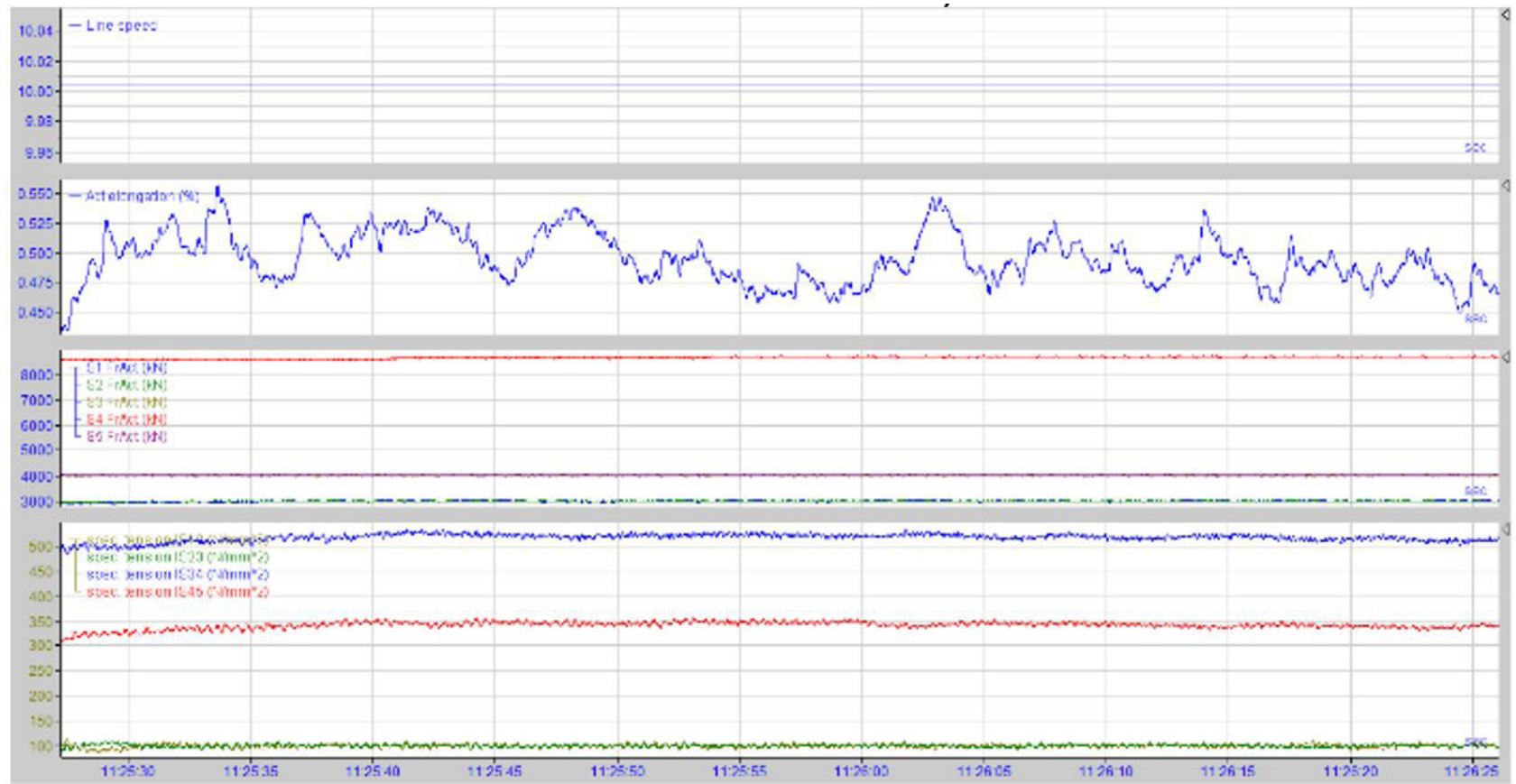

Figure 7. Skin Pass of MI 250 width II $50 \mathrm{~mm}$ thickness $0.90 \mathrm{~mm}$ on TCM. 
In case that limits of the inter stand tension are reached (max. approx. $600 \mathrm{~N} / \mathrm{mm}^{2}$, min. approx. $120 \mathrm{~N} / \mathrm{mm}^{2}$ ) a roll force spill-over function is used to bring the inter stand tension back to the operational range.

\section{RESULT AND CONCLUSION}

The Figure 7 shows as an example for skin pass operation of a martensitic strip (steel grade MI250 width $1150 \mathrm{~mm}$ and $0.9 \mathrm{~mm}$ thickness) on a 5 stand tandem mill.
The strip flatness has been improved without changing the mechanical properties. From the operational point of view the workflow and automatic functions like threading and tailing of the mill can be done in fully automatic like in the original use as reduction mill.

The result proves that the tandem mill in regular production downtime can be used for pure skin pass operation without bigger investments costs fulfilling the actual and future market demands for high strength steel. Also that the precise set-up strategies and flatness setting by applying FEM and FVM method, gives the operational safety and opportunity to utilize the whole design limits and event further of the installed mill.

\section{REFERENCES}

I Bathe KJ. Finite-elemente-methoden. Berlin: Springer-Verlag; 1990.

2 Ferziger JH, Perić M, Street RL. Computational methods for fluid dynamics. Cham: Springer-Verlag; 2002.

3 Kunz J, Maria E. Die Abplattung im Kontaktproblem paralleler Zylinder. Forschung im Ingenieurwesen. 2002;67(4): I46-I56.

Received: 7 Dec. 2019

Accepted: 24 Dec. 2019 